\title{
Effect of weight-bearing activities on bone mineral density in spinal cord injured patients during the period of the first two years
}

\author{
V Alekna $^{1,2}$, M Tamulaitiene ${ }^{1,2,3}$, T Sinevicius ${ }^{1,4}$ and A Juocevicius ${ }^{1,4}$ \\ ${ }^{1}$ Faculty of Medicine, Vilnius University, Vilnius, Lithuania; ${ }^{2}$ Institute of Clinical and Experimental Medicine at Vilnius University, \\ Vilnius, Lithuania; ${ }^{3}$ National Osteoporosis Center, Vilnius, Lithuania and ${ }^{4}$ Vilnius University Hospital Santariskiu Klinikos, Vilnius, \\ Lithuania
}

Study design: Prospective study on patients with spinal cord injuries.

Objectives: To evaluate the loss of bone mineral density (BMD) in various body regions of patients with spinal cord injury ( $\mathrm{SCl}$ ) and its dependence on weight bearing activities during 2 years post injury. Methods: BMD of the whole body was measured in patients with $\mathrm{SCl}$. Baseline measurement was performed in 6-16 weeks after SCl, the second and the third-respectively 12 and 24 months after injury. Fifty-four subjects were selected and divided into two groups: standing and non-standing. From these groups 27 pairs were made according to gender, age and height.

Results: There was found to be a well-marked decrease in BMD values for lower extremities, but there was no significant difference between paraplegic and tetraplegic patients 1 and 2 year after injury. Leg BMD reduced by $19.62 \%(95 \% \mathrm{Cl}, 17-22 \%)$ in the standing group and by $24 \%(95 \% \mathrm{Cl}, 21-27 \%)$ in non-standing group during the first year. Two years after $\mathrm{SCl}$ patients in standing group had significantly higher leg $\mathrm{BMD}-1.018 \mathrm{~g} / \mathrm{cm}^{2}\left(95 \% \mathrm{Cl}, 0.971-1.055 \mathrm{~g} / \mathrm{cm}^{2}\right)$ than in the non-standing group $-0.91 \mathrm{~g} / \mathrm{cm}^{2}\left(95 \% \mathrm{Cl}, 0.872-0.958 \mathrm{~g} / \mathrm{cm}^{2}\right)(P \leqslant 0.0001)$.

Conclusion: $\mathrm{SCl}$ patients who performed daily standing $\geqslant 1 \mathrm{~h}$ and not less than 5 days per week, had significantly higher BMD in the lower extremities after 2 years in comparison to those patients who did not perform standing.

Spinal Cord (2008) 46, 727-732; doi:10.1038/sc.2008.36; published online 29 April 2008

Keywords: spinal cord injury; bone mineral density; dual energy X-ray absorptiometry; weight-bearing activity

\section{Introduction}

Disuse bone loss is a known consequence of spinal cord injury (SCI) and occurs in almost every spinal cord injured patient. ${ }^{1,2}$ Several factors appear to have a major influence on bone mineral density (BMD) in SCI individuals, such as level and type according to ASIA Impairment Scale (AIS) ${ }^{3}$ of injury, muscle spasticity, age, gender and time passed after SCI. The level of spinal cord lesion and thus extent of impairment of motor and sensory function may be taken into account because tetraplegics are more likely to loose bone mass than paraplegics. ${ }^{4-7}$ The high fracture was reported in SCI individuals. ${ }^{8}$

A number of studies have been conducted on weightbearing effects on bone mass at different skeletal sites. ${ }^{9-14}$ Some studies ${ }^{15,16}$ have shown the influence of passive weight-bearing on $\mathrm{BMD}$, but these findings were not confirmed by other researchers. ${ }^{17-20}$

Correspondence: Dr V Alekna, Medical Faculty, Vilnius University, Zygimantu street 9, Vilnius LT-01102, Lithuania.

E-mail: vidmantas.alekna@ekmi.vu.It

Received 3 August 2007; revised 5 March 2008; accepted 26 March 2008; published online 29 April 2008
The aim of the study was to assess bone loss in persons with SCI and its dependence on weight-bearing activity (passive standing) during the first 2 years post injury.

\section{Methods}

Subjects with newly occurred SCI were invited to take part in the study at the Department of Rehabilitation, Physical and Sport Medicine of Vilnius University Hospital Santariskiu klinikos. The study was approved by the Lithuanian Bioethics Committee.

Patients with traumatic SCI with complete motor lesion (type A and B of AIS) who agreed to take part in the study were selected. Postmenopausal women, individuals younger than 20 years of age and patients with non-traumatic SCI were not included. Persons also were not included when they reported any diseases or conditions interfering with bone metabolism - metabolic bone diseases, cancer, rheumatic and endocrinologic diseases. No specific medication affecting bone metabolism (estrogens, bisphosphonates, SERMs, strontium ranelate, calcitonin) was used by patients. Vitamin 
D and Calcium supplementation was not taken into account in this study.

At initial evaluation age, body weight and height, date of injury and SCI level were recorded for each patient. Before the SCI all patients were physically and socially active people. The severity of SCI was evaluated according to International standards for neurological classification of SCI.

All patients underwent standard rehabilitation program for SCI patients at the rehabilitation department, average duration of rehabilitation was 105 days. Rehabilitation program included physiotherapy two times per day, occupational therapy, massage, psychological and social help, as well as teaching the patient family members. Regular passive standing in special frame was started at the rehabilitation department 8-12 weeks after the SCI. All patients were instructed to continue standing at home daily for at least $1 \mathrm{~h}$, after discharge from the rehabilitation unit.

The second and the third examinations were performed at the same rehabilitation department 12 and 24 months after SCI, respectively. Physical activity was assessed by self-report concerning duration and frequency of standing. Those individuals who reported standing in standing frame at least $1 \mathrm{~h}$ per day not less than 5 days per week were assigned to group A (standing group). Subjects were considered to belong to non-standing group (group B) if they did not perform standing at all after discharge from the rehabilitation unit. The main reason for not standing was lack of patient's and his family motivation, but not severe disabling diseases. Each patient of standing group was gender-, age( \pm 3 years) and height- $( \pm 6 \mathrm{~cm}$ ) matched with a patient from non-standing group using the baseline data.

Bone mineral density was assessed at the National Osteoporosis Center using dual-energy X-ray absorptiometry (DXA) on DPX-IQ (GE Lunar, Madison, WI, USA). Total body BMD was measured and four different regions - arms, legs, pelvis and lumbar spine (L2-L4) - were evaluated. The arm region included the humerus, radius, ulna and hand bones. The leg region included the femur, tibia, fibula and foot bones. The initial BMD measurement was performed 6-16 weeks after injury - as soon as patient's physical condition allowed. The second and the third assessments were performed 12 and 24 months ( \pm 3 months) after SCI. All measurements were performed by the same technician on the same DXA device.

Statistical analysis was performed using the software 'SPSS 12.0 for Windows'. Data dispersion was checked using $\chi^{2}$ criterion. All the measurement results are presented as mean \pm s.d. Statistical analysis was made using an independent $t$-test (Student's test) and multivariate multiple regression. The level of statistical significance was set at $P \leqslant 0.05$ with $95 \%$ confidence interval (CI) of the difference.

\section{Results}

Of the 83 patients initially invited 19 subjects were excluded: one patient died because of sepsis, 11 did not come for further examinations because of health problems (urinary tract infection, pneumonia). Seven subjects significantly changed the standing regimen (performed daily standing less than $1 \mathrm{~h}$ and/or less than 5 days per week) and were excluded.

Among 64 patients investigated there were 29 patients in standing group A and 35 patients in group B. According to grouping criteria 27 pairs were made after the third examination. There was no possibility to find the right pair for 10 subjects and they were excluded from the present analysis. Among 54 patients analyzed 10 (19\%) were women, mean age $37.3 \pm 10.0$ years, range $20-50$ years and $44(81 \%)$ men, mean age $33.4 \pm 12.0$ years, range $20-63$ years.

Table 1 shows the characteristics of the paired subjects. There were no statistically significant differences in age, gender, weight and height between the paired groups at initial (baseline) examination.

The highest SCI level was C2 and the lowest-L1. Paraplegia (lesion at Th1 and lower) was determined for 2 women and 31 men. Tetraplegia (higher lesion than Th1) was determined for eight women and 13 men. Mean age of paraplegic patients was $31.8 \pm 10.5$ years in group $\mathrm{A}$, and $33.6 \pm 13.2$ years in group $B$. In tetraplegic patients mean age was $36.5 \pm 13.5$ years in group $A$ and $33.8 \pm 10.3$ years in group $\mathrm{B}$.

Table 2 shows the results of DXA measurements performed at the beginning of the study, 1 year later and 2 years later, depending on injury level. We compared BMD at the same skeletal sites between paraplegics and tetraplegics within standing and non-standing groups. No statistically significant BMD differences were found in arms, legs, pelvis, spine and the total body between paraplegic and tetraplegic patients at all three measurements. These results demonstrate that BMD decrease does not depend on SCI level. Calculated multivariate multiple regression model

Table 1 Characteristics of paired spinal cord injured persons (mean \pm s.d.)

\begin{tabular}{|c|c|c|c|}
\hline Parameters & $\begin{array}{c}\text { Group } A \text { (standing) } \\
(\mathrm{n}=27)\end{array}$ & $\begin{array}{c}\text { Group } B \text { (non-standing) } \\
(\mathrm{n}=27)\end{array}$ & P-value \\
\hline Number of persons (female/male) & $27(5 / 22)$ & $27(5 / 22)$ & - \\
\hline Age (years) & $34.6 \pm 12.4$ & $33.7 \pm 11.4$ & 0.79 \\
\hline Height (cm) & $174.4 \pm 8.5$ & $175.0 \pm 7.3$ & 0.78 \\
\hline Weight $(\mathrm{kg})$ & $71.6 \pm 11.8$ & $71.0 \pm 12.0$ & 0.84 \\
\hline $\begin{array}{l}\text { Number of weeks between } \mathrm{SCl} \text { and } \\
\text { the initial BMD assessment }\end{array}$ & $11.3 \pm 3.19$ & $11.2 \pm 3.2$ & 0.93 \\
\hline Number of tetraplegics & 10 & 11 & - \\
\hline Number of paraplegics & 17 & 16 & - \\
\hline
\end{tabular}


Table 2 Bone mineral density (BMD) for total body and skeletal regions for paraplegic and tetraplegic spinal cord injured persons in standing (Group A) and non-standing (Group B) patients

\begin{tabular}{|c|c|c|c|c|c|c|}
\hline \multirow[t]{3}{*}{ Skeletal regions } & \multicolumn{3}{|c|}{ Group A } & \multicolumn{3}{|c|}{ Group B } \\
\hline & Paraplegics & Tetraplegics & $P$ & Paraplegics & Tetraplegics & $P$ \\
\hline & $\mathrm{n}=17$ & $\mathrm{n}=10$ & & $\mathrm{n}=16$ & $\mathrm{n}=11$ & \\
\hline \multicolumn{7}{|c|}{$B M D\left(\mathrm{~g} / \mathrm{cm}^{2}\right)$ at the baseline (first measurement) } \\
\hline Arm & $0.992 \pm 0.084$ & $1.034 \pm 0.047$ & 0.16 & $1.025 \pm 0.086$ & $1.098 \pm 0.246$ & 0.33 \\
\hline Leg & $1.346 \pm 0.106$ & $1.373 \pm 0.084$ & 0.50 & $1.350 \pm 0.051$ & $1.391 \pm 0.088$ & 0.19 \\
\hline Pelvis & $1.174 \pm 0.144$ & $1.187 \pm 0.146$ & 0.74 & $1.285 \pm 0.268$ & $1.151 \pm 0.111$ & 0.07 \\
\hline Lumbar spine & $1.270 \pm 0.112$ & $1.286 \pm 0.15$ & 0.76 & $1.275 \pm 0.11$ & $1.256 \pm 0.119$ & 0.66 \\
\hline Total body & $1.262 \pm 0.092$ & $1.247 \pm 0.05$ & 0.64 & $1.250 \pm 0.077$ & $1.271 \pm 0.06$ & 0.46 \\
\hline \multicolumn{7}{|c|}{ BMD $\left(\mathrm{g} / \mathrm{cm}^{2}\right)$ after 1 year (second measurement) } \\
\hline Arm & $0.954 \pm 0.074$ & $0.966 \pm 0.062$ & 0.67 & $0.913 \pm 0.114$ & $0.959 \pm 0.098$ & 0.23 \\
\hline Leg & $1.091 \pm 0.123$ & $1.088 \pm 0.089$ & 0.95 & $1.048 \pm 0.116$ & $1.043 \pm 0.104$ & 1.00 \\
\hline Pelvis & $1.046 \pm 0.117$ & $1.015 \pm 0.082$ & 0.47 & $0.983 \pm 0.099$ & $1.006 \pm 0.112$ & 0.64 \\
\hline Lumbar spine & $1.120 \pm 0.134$ & $1.153 \pm 0.175$ & 0.59 & $1.101 \pm 0.136$ & $1.081 \pm 0.119$ & 0.69 \\
\hline Total body & $1.154 \pm 0.058$ & $1.129 \pm 0.058$ & 0.29 & $1.098 \pm 0.077$ & $1.119 \pm 0.064$ & 0.66 \\
\hline \multicolumn{7}{|c|}{$B M D\left(\mathrm{~g} / \mathrm{cm}^{2}\right)$ after 2 years (third measurement) } \\
\hline Arm & $0.981 \pm 0.075$ & $0.960 \pm 0.077$ & 0.50 & $0.922 \pm 0.137$ & $0.895 \pm 0.146$ & 0.67 \\
\hline Leg & $1.024 \pm 0.119$ & $1.007 \pm 0.066$ & 0.69 & $0.887 \pm 0.063$ & $0.943 \pm 0.151$ & 0.27 \\
\hline Pelvis & $1.015 \pm 0.117$ & $0.981 \pm 0.085$ & 0.43 & $0.936 \pm 0.094$ & $0.931 \pm 0.094$ & 0.90 \\
\hline Lumbar spine & $1.093 \pm 0.118$ & $1.092 \pm 0.167$ & 0.98 & $1.078 \pm 0.166$ & $1.014 \pm 0.128$ & 0.29 \\
\hline Total body & $1.126 \pm 0.053$ & $1.099 \pm 0.056$ & 0.22 & $1.087 \pm 0.053$ & $1.063 \pm 0.071$ & 0.32 \\
\hline
\end{tabular}

confirmed that only standing was significant predictor for BMD in legs $(P=0.0003)$, pelvis $(P=0.02)$ and the total body $(P=0.02)$ at the third measurement. Other factors including age, gender and SCI level did not have statistically significant impact on BMD at the third measurement. Therefore, further tetraplegic patients were analyzed together with paraplegic patients.

Table 3 shows the results of DXA measurements performed at the beginning of the study in standing and non-standing groups. No statistically significant differences in BMD were found between groups of all evaluated skeletal sites at the first measurement.

Bone densitometry showed statistically significantly reduced values for different skeletal regions a year after injury, independently of weight-bearing activities (Table 4). Leg BMD decreased by $19.62 \%$ (95\% CI, 17-22\%) in the group A and by $24 \%$ (95\% CI, 21-27\%) in group B during the first year. BMD of pelvis reduced by $12.37 \%$ (95\% CI, 9-15\%) in group A, and by $15.22 \%$ (95\% CI, 11-21\%) in group B. More reduced BMD was found 2 years after injury. Statistically significant difference was found in legs and pelvis when compared with the second and the third measurement results within groups $\mathrm{A}$ and $\mathrm{B}$.

Statistically significantly greater reduction of BMD was noticed in the legs and pelvis during the second year (BMD difference between second and the third measurement) in group B than in group A. The effect of passive standing on BMD in different skeletal sites is shown in Figure 1.

No statistically significant differences between standing and non-standing patients were found 1 year after SCI. After 2 years patients in standing group had statistically significantly higher BMD in the legs $-1.018 \mathrm{~g} / \mathrm{cm}^{2}$ (95\% CI, $\left.0.971-1.055 \mathrm{~g} / \mathrm{cm}^{2}, P=0.0004\right)$ and in the pelvis $-1.002 \mathrm{~g} / \mathrm{cm}^{2}$
Table 3 Bone mineral density (mean \pm s.d.) for total body and skeletal regions for spinal cord injured patients in standing (Group $A$ ) and nonstanding (Group B) groups on baseline

\begin{tabular}{lccc}
\hline Skeletal regions & \multicolumn{2}{c}{ Bone mineral density $\left(\mathrm{g} / \mathrm{cm}^{2}\right)$} & \multirow{2}{*}{ P-value } \\
\cline { 2 - 3 } & Group $A(\mathrm{n}=27)$ & Group $B(\mathrm{n}=27)$ & \\
\hline Arm & $1.008 \pm 0.075$ & $1.029 \pm 0.075$ & 0.30 \\
Leg & $1.356 \pm 0.098$ & $1.375 \pm 0.077$ & 0.41 \\
Pelvis & $1.180 \pm 0.142$ & $1.176 \pm 0.122$ & 0.92 \\
Lumbar spine & $1.276 \pm 0.125$ & $1.264 \pm 0.114$ & 0.72 \\
Total body & $1.257 \pm 0.079$ & $1.260 \pm 0.071$ & 0.85 \\
\hline
\end{tabular}

(95\% CI, 0.960-1.044 $\left.\mathrm{g} / \mathrm{cm}^{2}, P=0.0144\right)$ in comparison with non-standing patients- $0.91 \mathrm{~g} / \mathrm{cm}^{2}\left(95 \% \mathrm{CI}, 0.872-0.958 \mathrm{~g} / \mathrm{cm}^{2}\right)$ and $0.934 \mathrm{~g} / \mathrm{cm}^{2}\left(95 \% \mathrm{CI}, 0.898-0.970 \mathrm{~g} / \mathrm{cm}^{2}\right)$, respectively. Statistically significant difference $(P=0.016)$ of total body BMD was found between group A $1.116 \mathrm{~g} / \mathrm{cm}^{2}(95 \%$ CI, $\left.1.094-1.137 \mathrm{~g} / \mathrm{cm}^{2}\right)$ and group B $1.077 \mathrm{~g} / \mathrm{cm}^{2}(95 \% \mathrm{CI}$, $\left.1.053-1.101 \mathrm{~g} / \mathrm{cm}^{2}\right)$. No statistically significant differences were found in BMD of other skeletal sites between standing and non-standing patients at last assessment.

\section{Discussion}

The present prospective study supports the evidence that significant bone mineral density decrease occurs in patients after spinal cord injury, and that the demineralization predominates in the lower limbs. In our study, between two groups there was no difference in the matching criteria (age, gender, height and weight), as well as in the type of 
Table 4 Decrease of bone mineral density (BMD, in \%) for total body and skeletal regions for patients during first year, second year and during two years after spinal cord injury in standing (Group A) and non-standing (Group B) groups

\begin{tabular}{lccccc}
\hline Skeletal regions & \multicolumn{3}{c}{ BMD decrease in Group $A$} & & BMD decrease in Group B \\
\cline { 2 - 4 } & $\begin{array}{c}\text { During first } \\
\text { year (\%) }\end{array}$ & $\begin{array}{c}\text { During second } \\
\text { year (\%) }\end{array}$ & $\begin{array}{c}\text { Per 2 years } \\
(\%)\end{array}$ & $\begin{array}{c}\text { During first } \\
\text { year (\%) }\end{array}$ & $\begin{array}{c}\text { During second } \\
\text { year (\%) }\end{array}$ \\
\hline Arm & 4.86 & 2.61 & 7.34 & 7.68 & 1.37 \\
Leg & $19.62^{\mathrm{a}}$ & $6.61^{\mathrm{b}}$ & $24.92^{\mathrm{c}}$ & $24.0^{\mathrm{a}}$ & $12.92^{\mathrm{b}}$ \\
Pelvis & 12.37 & $3.10^{\mathrm{b}}$ & $15.09^{\mathrm{c}}$ & 15.22 & $3.32^{\mathrm{b}}$ \\
Lumbar spine & 11.29 & 3.45 & 14.34 & 13.84 & 3.94 \\
Total body & $8.92^{\mathrm{a}}$ & 2.45 & $11.15^{\mathrm{c}}$ & $11.98^{\mathrm{a}}$ & $20.58^{\mathrm{c}}$ \\
\hline
\end{tabular}

${ }^{a}$ Significant difference between baseline and second measurement.

${ }^{\mathrm{b} S}$ Significant difference between second and third measurement.

cSignificant difference between baseline and third measurement.

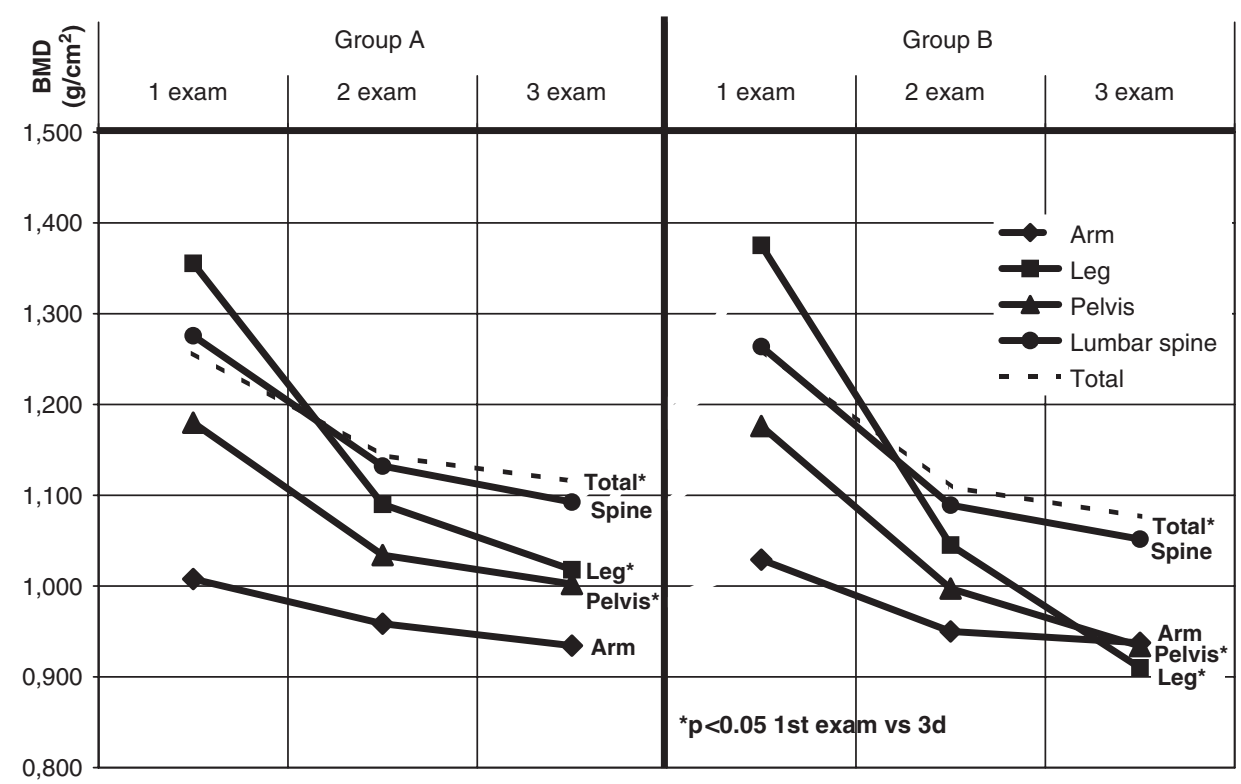

Figure 1 Bone mineral density on baseline, in 1 year (second exam) and in 2 years (third exam) after spinal cord injury for total body and different skeletal sites in standing (Group $A$ ) and non-standing (Group B) patients $\left(\mathrm{g} / \mathrm{cm}^{2}\right) .{ }^{*} P<0,05$ first exam versus third exam.

injury and duration of immobilization. A difficulty of direct comparison with other studies is caused by different number of patients investigated, extent of neurological involvement, the duration of injury, physical activity levels of patients. We could not find any data on initial BMD in SCI patients with the mean postlesional duration of up to 12 weeks.

Immobilization by SCI causes general bone loss, which ranges from 30 to $50 \% .^{2,8-11}$ The results of our study confirm that there is a significant decrease of bone mass in patients after SCI, especially rapid in lower extremities. Biering - Sorensen et al. reported 50\% BMD decrease in paralyzed extremities during 3 years longitudinal study. ${ }^{14}$ Leg BMD of our patients reduced by $34 \%$ per 2 years, on average. Such difference may be due to the longer duration of SCI and to the method of BMD evaluation - in the aforementioned study BMD was evaluated by age-matched BMD (Z-score) and in our study datum-level was the first BMD result, accomplished on average in 11 weeks after SCI. Moreover, it is determined that intensive bone loss starts immediately after SCI (from 0.9 to $2 \%$ per month, during the first months). ${ }^{13}$ So it might be stated, that at the first examination our patients could have some amount of bone loss, which led to the fact that the difference between the first and later results was less.

The present study agrees with the premise, that the bone loss mostly occurs because of immobilization during the first year after SCI. Garland et al. ${ }^{2}$ noted that BMD loss might be found in femur during 4-16 months after SCI. Kiratli ${ }^{13}$ has shown that the bone loss starts suddenly after the injury, in average $2 \%$ per month during the first 4-6 months, more in femur and about $1 \%$ per month during the last part of the first year. Later this process gets slower. Jones et al. ${ }^{20}$ determined progressive bone mineral loss in paralyzed extremities from the injury start. The mean percentage of BMD decrease in our patients was $24 \%$ in lower extremities and $15.22 \%$ in pelvis during the first year after SCI, 
independently of injury level. During the second year bone demineralization developed slower-BMD of our patients reduced by $12.92 \%$ in the lower extremities, and only by $6.32 \%$ in pelvis.

The literature states that bone demineralization degree in the paralyzed extremities does not depend on injury level, ${ }^{4,8}$ and tetraplegic patients were examined together with paraplegic patients. In the present study also no significant differences were found between tetraplegic and paraplegic patients for any of the regional BMD values, and the data for these two groups were pooled. Our study shows that the most bone demineralization is found in lower extremities in paraplegic patients as well as in tetraplegics. Recent studies of other authors, ${ }^{2,20}$ which reported higher osteopenia degree in the paralyzed lower extremities than in other skeleton regions, are coincident with our study.

Some researchers ${ }^{15,16}$ demonstrate beneficial effects of standing on bone turnover. During the mechanical load a power vector is directed through the bone trabecules in the way, that minimum effective load is stimulating bone renovation. ${ }^{9}$ Goemaere et al. ${ }^{15}$ showed that femoral shaft BMD of the patients regularly performing passive weightbearing standing was higher than those of non standing patients and they recommend using long leg braces. Our study also illustrates higher BMD in the lower extremities for the patients performing standing in comparison to those not standing. This is in contrast to a number of studies, which have shown no significant impact of weight bearing on leg BMD in chronic SCI patients. ${ }^{17-20}$ It should be noted that in those studies the SCI patients have long postlesional duration. Needham-Shropshire et $a l^{18}$ have not found positive effect of standing on bone mineral mass that confronts with our study. The differences observed could be explained by different methods. In the above-mentioned study a small number of patients (three women and 13 men) were observed, and static loading was started later: an average period was 3.8 years after SCI. In our study, passive standing was started as early as possible-within 4 months after SCI.

Jones et al. ${ }^{14}$ studied physical exercises effect on BMD for paraplegic and tetraplegic patients after SCI and determined that intensive physical activity not less than 60 min per day prevent bone loss in the arms but does not preserve bone mass in the lower body. Authors compared the BMD in the same regions (arms, legs, lumbar spine) as we did, but the patients investigated have performed other kind of physical activity - they were highly active individuals. The SCI patients were compared to healthy persons, and in our study the BMD change was analyzed comparing initial and 2 years results in standing and non-standing SCI patients.

Lazo et al. ${ }^{8}$ reported a high frequency of fracture in SCI persons. Researchers have shown that fracture frequency increased when BMD was lower than $1.0 \mathrm{~g} / \mathrm{cm}^{2}$ and fracture risk increased 2.2 times when BMD reduced by $0.1 \mathrm{~g} / \mathrm{cm}^{2} .{ }^{8} \mathrm{In}$ this study, the mean leg BMD was greater than $1.0 \mathrm{~g} / \mathrm{cm}^{2}$ in standing patients and thus the fracture risk should be reduced.

There are some limitations of this study. There was no possibility to randomize patients and to control the weight- bearing activity. We could not recommend patients not to stand at home, and standing and non-standing groups were made after 2 years by self-reporting. Another limitation is that we have not taken into consideration a physical activity other than standing.

In conclusion, the present study showed bone loss after spinal cord injury, but BMD decreases unequally in different skeletal sites. The highest bone loss (on average $34 \%$ per 2 years) was detected in the legs. The results of our study show that weight-bearing activity prevents development of disuse bone loss in the lower extremities. Everyday standing $\geqslant 1 \mathrm{~h}$ and not less than 5 days per week had a positive impact on bone mineral density in SCI patients with paraplegia and tetraplegia, but is not able to maintain or increase it.

\section{Acknowledgements}

We gratefully acknowledge the help of Natalija Daniliuk from the Institute of Clinical and Experimental Medicine for helping with statistical analysis. We thank the medical staff at the Rehabilitation Department at Vilnius University Hospital Santariskiu klinikos.

\section{References}

1 Szollar SM. Demineralization in tetraplegic and paraplegic man over time. Spinal Cord 1997; 35: 223-228.

2 Garland D, Steward C, Adkins R, Hu S, Rosen C, Liotta F et al. Osteoporosis after spinal cord injury. J Orthop Res 1992; 10: 371-378.

3 Marino RJ, Barros T, Biering-Sorensen F, Burns SP, Donovan WH, Graves DE et al. International standards for neurological classification of spinal cord injury. J Spinal Cord Med 2003; 26 (suppl 1): S50-S56.

4 Dauty M, Perrouin Verbe B, Maugars Y, Dubois C, Mathe JF. Supralesional and sublesional bone mineral density in spinal cord-injured patients. Bone 2000; 27: 305-309.

5 Demirel G, Yilmaz H, Paker N, Onel S. Osteoporosis after spinal cord injury. Spinal Cord 1998; 36: 822-825.

6 Tsuzuku S, Ikegami Y, Yabe K. Bone mineral density difference between paraplegic and quadriplegic patients: a cross-sectional study. Spinal Cord 1999; 37: 358-361.

7 Garland DE, Adkins RH, Stewart CA, Ashford R, Vigil D. Regional osteoporosis in women who have a complete spinal cord injury. J Bone Joint Surg [Am] 2001; 83: 1195-1200.

8 Lazo MG, Shirazi P, Sam M, Giobbie-Hurder A, Blacconiere MJ, Muppidi M. Osteoporosis and risk of fracture in men with spinal cord injury. Spinal Cord 2001; 39: 208-214.

9 Frost HM. Perspectives: bone's mechanical usage windows. Bone Miner 1992; 19: 257-271.

10 Biering-Sorensen F, Bohr H. Bone mineral content of the lumbar spine and lower extremities years after spine cord lesion. Paraplegia 1988; 26: 293-301.

11 Gutin B, Kasper MJ. Can vigorous exercise play a role in osteoporosis prevention? A review. Osteoporosis Int 1992; 2: 55-69.

12 Whalen RT, Arnaud SB, Grindeland RE. Proceedings of the NASA symposium on the influence of gravity and activity on muscle and bone. J Biomech 1991; 24: 1-178.

13 Kiratli BJ. Skeletal Adaptation to Disuse: Longitudinal and Crosssectional Study of the Response of the Femur and Spine to Immobilization (Paralysis). University of Wisconsin: Madison, WI, 1989.

14 Biering-Sorensen F, Bohr H, Schaadt O. Longitudinal study of bone mineral content in the lumbar spine, the forearm and the 
lower extremities after spinal cord injury. Eur J Clin Invest 1990; 20: 330-335

15 Goemaere S, Van Laere M, De Neve P, Kaufman JM. Bone mineral status in paraplegic patients who do or do not perform standing. Osteoporosis Int 1994; 4: 138-143.

16 Kaplan PE, Roden W, Gilbert E, Richards L, Goldschmidt JW. Reduction of hypercalciuria in tetraplegia after weight-bearing and strengthening exercises. Paraplegia 1981; 19: 289-293.

17 Kunkel CF, Scremin E, Eisenberg B, Garcia JF, Roberts S, Martinez S. Effect of 'standing' on spasticity, contracture, and osteoporosis in paralysed males. Arch Phys Med Rehab 1993; 74: 73-78.
18 Needham-Shropshire BM, Broton JG, Klose KJ, Lebwohl N, Guest RS, Jacobs PL. Evaluation of a training program for persons with SCI paraplegia using the Parastep 1 ambulation system: part 3. Lack of effect on bone mineral density. Arch Phys Med Rehab 1997; 78: 799-803.

19 Wood DE, Dunkerley AL, Tromans AM. Results from bone mineral density scans in twenty-two complete lesion paraplegics. Spinal Cord 2001; 139: 145-148.

20 Jones LM, Legge $M$, Goulding A. Intensive exercise may preserve bone mass of the upper limbs in spinal cord injured males but does not retard demineralisation of the lower body. Spinal Cord 2002; 40: 210-235 